\title{
Sistem Dokumentasi Rancang Bangun Pesawat Udara Berbasis Web Menggunakan Framework CodeIgniter dan PostgreSQL dengan Metode Prototype
}

\author{
Abdul Aziz ${ }^{1}$ Hartono $^{2}$, Abdul Rohman ${ }^{3}$, Danartomo Kusumoaji ${ }^{4}$ \\ 1,2,3,4Pusat Teknologi Penerbangan, LAPAN, Jl. Raya LAPAN Rumpin Bogor, Indonesia, 16350

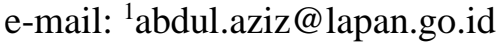

Submitted Date: July $14^{\text {th }}, 2020$

Revised Date: September $23^{\text {rd }}, 2020$
Reviewed Date: September 22 $2^{\text {nd }}, 2020$

Accepted Date: September 30 ${ }^{\text {th }}, 2020$

\begin{abstract}
The aircraft design is required to carry out the functions of the Design Organization Approval (DOA), in which there are several positions involved, namely Design Engineer (DE), Compliance Verification Engineer (CVE) and Airworthiness Officer (AWO). In the process, DE makes aircraft designs, CVE will correct the designs that have been made, and AWO will make corrections based on document writing standards. The current problem is that the document checking process takes a long time and requires excessive costs for the use of paper and ink. The solution to solve this problem is by building a web-based system. The system was built using the CodeIgniter framework and PostgreSQL as its database. As for the development of the system itself using the Prototype method. Through this system, the DOA function process will be faster and paperless.
\end{abstract}

Keywords: CodeIgniter; PostgreSQL; Prototype; DOA

\section{Abstrak}

Dalam rancang bangun pesawat udara dituntut untuk menjalankan fungsi Design Organization Approval (DOA), yang mana terdapat beberapa jabatan yang terlibat yaitu Design Engineer (DE), Compliance Verification Engineer (CVE) dan Airworthiness Officer (AWO). Secara prosesnya DE membuat desain pesawat, CVE akan mengkoreksi desain yang telah dibuat, dan AWO akan mengkoreksi berdasarkan standar penulisan dokumen. Permasalahan yang ada saat ini yaitu proses pengecekan dokumen membutuhkan waktu yang lama dan membutuhkan biaya berlebih untuk penggunaan kertas dan tinta. Solusi untuk mengatasi permasalahan tersebut yaitu dengan membangun sistem berbasis web. Sistem yang dibangun menggunakan framework CodeIgniter dan PostgreSQL sebagai basis datanya. Sedangkan untuk pengembangan sistem sendiri menggunakan metode Prototype. Melalui sistem ini proses fungsi DOA akan semakin cepat dan paperless.

Keywords: CodeIgniter; PostgreSQL; Prototype; DOA

\section{Pendahuluan}

Pusat Teknologi Penerbangan merupakan satuan kerja LAPAN yang salah satu fokusnya yaitu melakukan penelitian dengan membuat pesawat udara. Dalam prosesnya rancang bangun pesawat ini diharuskan menjalankan fungsi Design Organization Approval (DOA), yang mana terdapat beberapa jabatan yang terlibat yaitu Design Engineer (DE), Compliance Verification Engineer (CVE) dan Airworthiness Officer (AWO). Secara prosesnya DE membuat desain pesawat, CVE akan mengkoreksi desain yang telah dibuat, dan AWO akan mengkoreksi berdasarkan standar penulisan dokumen. Secara detail fungsi DOA dapat dilihat pada regulasi CASR part 21 Subpart J.

Sistem yang ada saat ini yaitu proses dilakukan tanpa komputerisasi melainkan dengan komunikasi secara langsung antara DE, CVE dan AWO. Pemeriksaan dokumen yang dilakukan oleh CVE dan AWO yaitu berupa dokumen desain yang telah dibuat dan dicetak oleh DE. Dokumen dicetak karena menghindari kebocoran dokumen 
jika dikirim secara digital menggunakan email atau aplikasi pengiriman data.

Adapun permasalahan yang terjadi yaitu proses pengecekan dokumen membutuhkan waktu yang lama. Pada proses ini terdapat waktu untuk melakukan percetakan dokumen yang dapat menghabiskan waktu berjam-jam, dan waktu pengecekan yang dilakukan oleh CVE dan AWO dapat menghabiskan waktu berhari-hari mulai dari proses pengajuan, pertemuan, pengecekan sampai hasil pengecekan. Selain itu, ada kebutuhan biaya berlebih untuk penggunaan kertas dan tinta untuk mencetak dokumen desain.

Hal ini mengakibatkan perlunya ada sistem yang dapat diakses dari mana saja guna efisiensi waktu dan juga paperless untuk mengurangi biaya operasional. Berdasarkan hal tersebut, penulis tertarik untuk membuat sistem dokumentasi yang berbasis website/ web. Website lebih mudah diakses oleh masyarakat di berbagai daerah hanya dengan menggunakan internet (Harminingtyas, 2018). Sehingga manfaat website ini dapat diterapkan agar DE, CVE dan AWO dapat mengakses sistem dari mana saja.

Adapun dalam membangun website ini, penulis menggunakan framework CodeIgniter karena pengerjaan website menjadi lebih cepat dibandingkan tanpa menggunakan framework. Framework memungkinkan kita membangun aplikasi dengan lebih cepat karena sebagai developer kita akan lebih memfokuskan pada pokok pemasalahan, sedangkan untuk hal-hal penunjang lainnya seperti koneksi ke database, form validation, GUI dan security umumnya telah disediakan oleh framework (Erinton, Negara, \& Sanjoyo, 2017). CodeIgniter menyediakan berbagai macam library yang dapat mempermudah dalam pengembangan dan termasuk framework tercepat dibandingkan dengan framework lainnya (Erinton, Negara, \& Sanjoyo, 2017).

Untuk keamanan data pada sistem ini, penulis akan mengimplementasikan website pada server yang hanya dapat diakses oleh jaringan kantor saja dan tidak dapat diakses oleh publik, guna mengurangi resiko peretasan dan kebocoran data. Seiring dengan kemajuan teknologi informasi maka sangat di perlukan sebuah keamanan data terhadap kerahasiaan informasi yang saling di pertukarkan melalui jaringan internet, apa lagi jika data tersebut dalam suatu jaringan komputer yang terhubung/terkoneksi dengan jaringan lain (Permana \& Nurnaningsih, 2018).

\section{Metode Penelitian}

\subsection{Metode}

Dalam metode pengembangan sistem, penulis menggunakan metode prototype. Penulis memilih metode prototype karena sistem ini melibatkan beberapa stackholder sehingga pengembang dan pelanggan bertemu dan mendefinisikan bersama keseluruhan sistem yang akan dibuat.

Prototype didefinisikan sebagai alat yang memberikan ide bagi pembuat maupun pemakai potensial tentang cara system berfungsi dalam bentuk lengkapnya, dan proses untuk menghasilkan sebuah prototype disebut prototyping (Fajarianto, 2016).

Untuk lebih lengkapnya metodologi penelitian berikut ini dapat dilihat pada Gambar 1 .

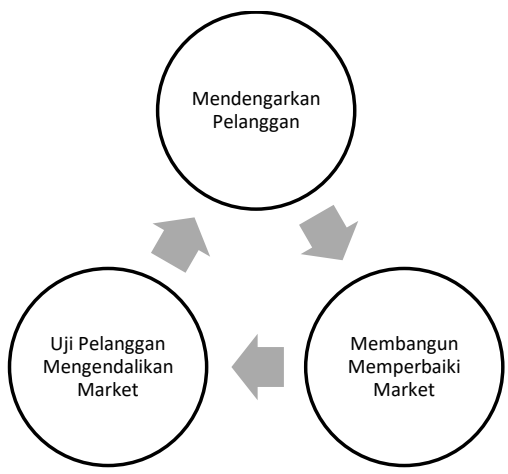

Gambar 1. Metode Prototype

Tahap yang pertama yaitu mendengarkan pelanggan. Pada tahap ini penulis mengumpulkan kebutuhan data untuk membangun sistem, dengan menggali informasi dari para stackholder terkait bagaimana gambaran sistem yang akan dibangun agar sistem dapat digunakan sesuai dengan kebutuhan.

Tahap yang kedua yaitu membangun memperbaiki market. Dalam membangun sistem dokumentasi ini, penulis membangun sistem yang berbasis web, web adalah sebuah software yang berfungsi untuk menampilkan dokumen-dokumen pada suatu web yang membuat pengguna dapat mengakses internet melalui software yang terkoneksi dengan internet (Destiningrum \& Adrian, 2017). Website ini dibangun menggunakan framework CodeIgniter, Framework adalah paket berisi fungsi-fungsi yang biasa digunakan dalam pembuatan aplikasi (Basuki, 2014). Untuk database penulis menggunakan PostgreSQL karena kebutuhan data yang banyak, PostgreSQL atau sering disebut 
Postgres merupakan salah satu dari sejumlah basisdata besar yang menawarkan skalabilitas, keluwesan, dan kinerja yang tinggi. Penggunaannya begitu meluas di berbagai platform dan didukung oleh banyak bahasa pemrograman (Dhining, Rokhayati, \& Kurniawan, 2017).

Tahap yang ketiga yaitu uji pelanggan mengendalikan market. Proses pengujian dilakukan menggunakan pengujian black-box untuk mengetahui apakah sistem sudah berjalan dengan benar. Teknik pengujian black-box yang berfokus kepada proses input dan output untuk memeriksa apakah program tersebut sesuai dengan hasil yang diharapkan (Ningrum, Suherman, Aryanti, Prasetya, \& Saifudin, 2019). Tahap ini mencoba sistem dan evaluasi prototype dengan cara menguji dengan studi kasus yang sudah dianalisis bersama-sama dengan stackholder. Jika pada tahapan ini merasa sistem belum sesuai dengan yang diinginkan, maka dapat dilakukan perbaikan website dengan kembali ke tahapan yang pertama.

\subsection{Analisis Sistem}

Analisis sistem dilakukan melalu proses identifikasi dan evaluasi masalah yang ada, kesempatan untuk solusi, hambatan yang akan terjadi juga kebutuhan yang diharapkan agar kemudian mengusulkan perbaikan-perbaikannya (Jogiyanto, 2017). Sistem yang peneliti usulkan, digambarkan dalam Use Case terlihat pada Gambar 2.

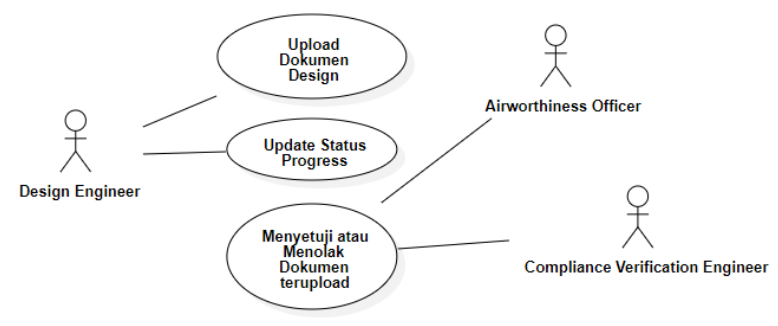

Gambar 2. Use Case Sistem

Dalam use case menggambarkan kegiatan utama yang dilakukan oleh masing-masing peran, agar mudah dimengerti terkait gambaran sistem yang menjalankan fungsi DOA.

\section{Hasil Penelitian}

Integrasi bentuk prototipe merupakan tahap selanjutnya untuk lanjutan rancang bangun dari sistem dokumentasi ini, tahap ini sebagai tahap saat suatu sistem sudah siap untuk diterapkan dengan keadaan sebenarnya. Sehingga dapat diperoleh informasi apabila sistem yang dirancang bangun sudah dapat menghasilkan tujuan yang tepat guna untuk menyelesaikan masalah penelitian (Kadir, 2017).

Berikut ini tabel untuk perangkat yang digunakan dalam integrasi prototipe.

Tabel 1. Rincian Kebutuhan Komputer

\begin{tabular}{|c|c|}
\hline Perangkat Keras & Spesifikasi \\
\hline Processor & $\begin{array}{lcr}\text { Intel(R) } & \text { Core(TM) } & \text { i3- } \\
6006 \mathrm{U} & \mathrm{CPU} & @ \\
2.00 \mathrm{GHz} & 1.99 \mathrm{GHz}\end{array}$ \\
\hline Hard Disk & 1TB \\
\hline Memory RAM & $4 \mathrm{~GB}$ \\
\hline Monitor & $\begin{array}{ll}15.6 "(16: 9) & \text { LED } \\
\text { backlit HD } & \end{array}$ \\
\hline Mouse & Standart \\
\hline Keyboard & Chiclet keyboard \\
\hline
\end{tabular}

Tabel 2. Rincian Perangkat Lunak (Software)

\begin{tabular}{|c|c|}
\hline Perangkat Lunak & Spesifikasi \\
\hline $\begin{array}{ll}\text { Sistem } & \text { Operasi } \\
\text { Komputer } & \end{array}$ & Windows 10 Pro 64-bit \\
\hline Web Browser & Mozilla Firefox 78.0.2 \\
\hline $\begin{array}{l}\text { Aplikasi Perancangan } \\
\text { Antar Muka }\end{array}$ & $\begin{array}{l}\text { Balsamiq } \quad \text { Mockups } \\
\text { 3.5.15 }\end{array}$ \\
\hline Aplikasi Pemodelan & StartUML 2.8.1 \\
\hline Web Server & Apache/2.4.27 \\
\hline Code Editor & Notepad++ 7.5.1 \\
\hline Bahasa Pemrograman & PHP 7.1.9 \\
\hline Framework & CodeIgniter 3.1.9 \\
\hline Database & PostgreSQL 9.5 \\
\hline
\end{tabular}

Pada tahap ini antarmuka yang dibuat setelah tahap perancangan. Adapun bentuk utama hasil implementasi adalah tampilan Tabel Dokumen desain, Halaman Detail Dokumen, Form Persetujuan, Timeline dan Diagram Progres.

Setelah login ke sistem, pengguna akan masuk ke halaman beranda yang di halaman tersebut terdapat tabel dokumen desain. Tabel dokumen berfungsi menampilkan semua dokumen desain yang harus dikerjakan oleh DE. Pada masing-masing dokumen sudah ditentukan penanggung jawab dari masing-masing posisi. 


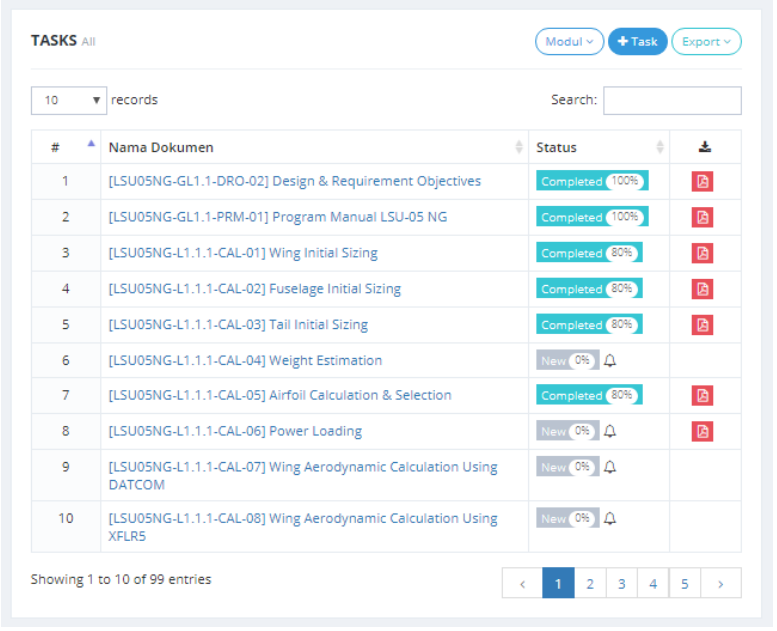

Gambar 3. Tabel Dokumen Desain

Pada tabel dokumen desain terdapat link ke halaman detail dokumen, halaman detail ini merupakan halaman utama dalam menjalankan fungsi DOA. Pada halaman tersebut DE mengunggah dokumen desain, lalu secara otomatis sistem akan meneruskan dokumen tersebut ke CVE untuk disetujui, dan tahap akhir akan disetujui oleh AWO. Pada sistem ini menunjukan dokumen desain sudah dalam bentuk digital, yang mana proses percetakan dokumen sudah tidak dilakukan sehingga mengefisiensikan penggunaan kertas dan tinta.

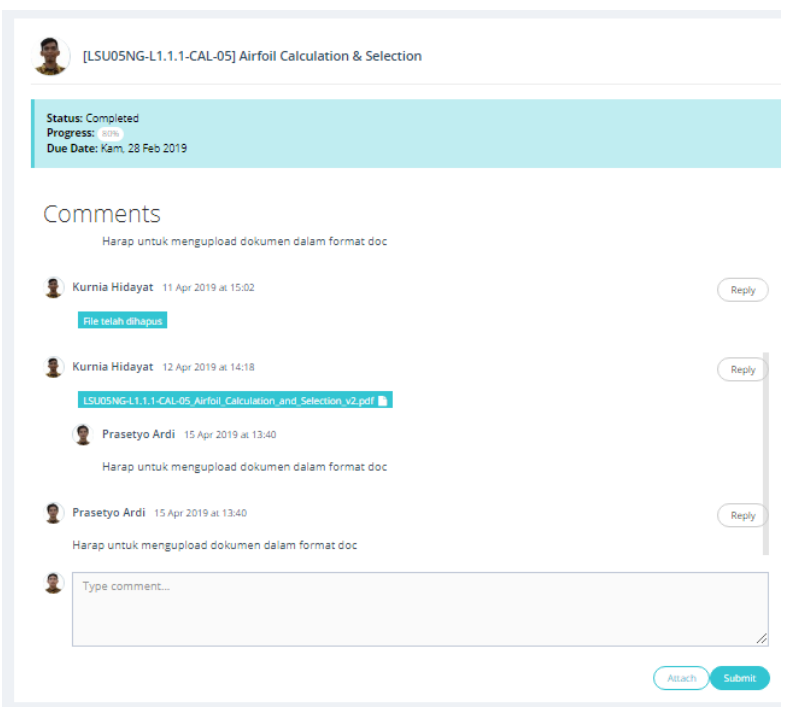

Gambar 4. Halaman Detail Dokumen

Untuk form persetujuan dokumen ditampilkan dengan pdf viewer, sehingga CVE dan AWO dapat mengkoreksi dokumen secara langsung. Dengan adanya fitur ini, mengurangi waktu proses pengecekan dokumen desain yang dilakukan oleh CVE dan AWO. Sehingga proses pengerjaan dokumen menjadi lebih cepat.

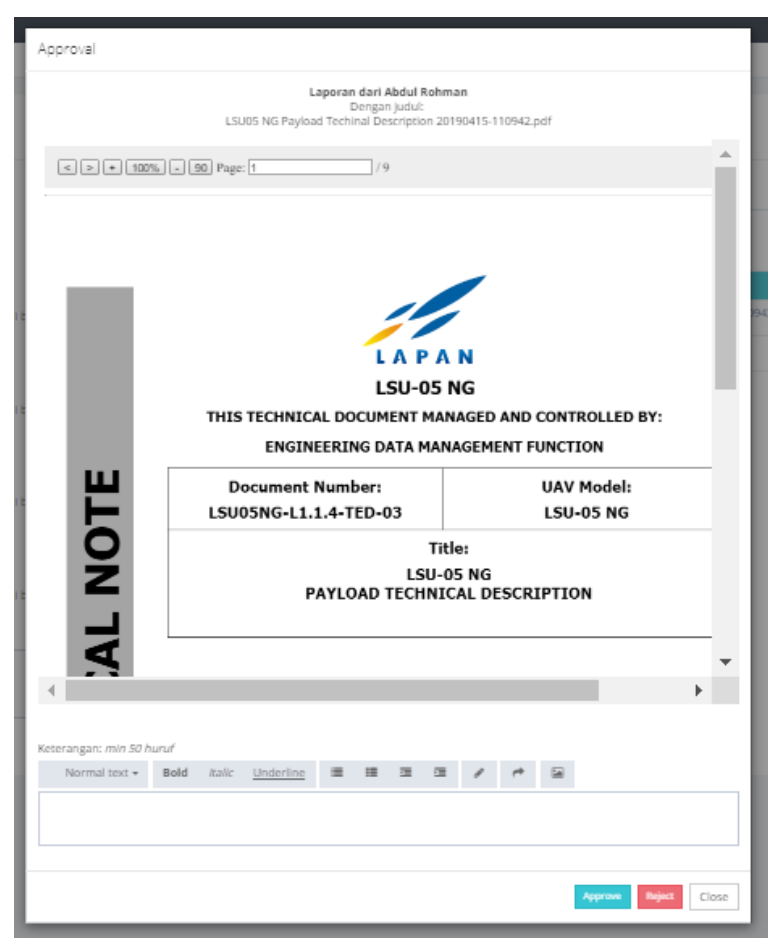

Gambar 5. Form Persetujuan

Pada halaman beranda terdapat timeline untuk mempermudah stackholder dalam mengetahui dokumen apa saja yang harus segera dikerjakan berdasarkan waktu pengerjaannya. Timeline ini dikelompokkan berdasarkan masingmasing tim, sehingga tim mana saja yang bertugas dalam membuat dokumen desain pada waktu tersebut.

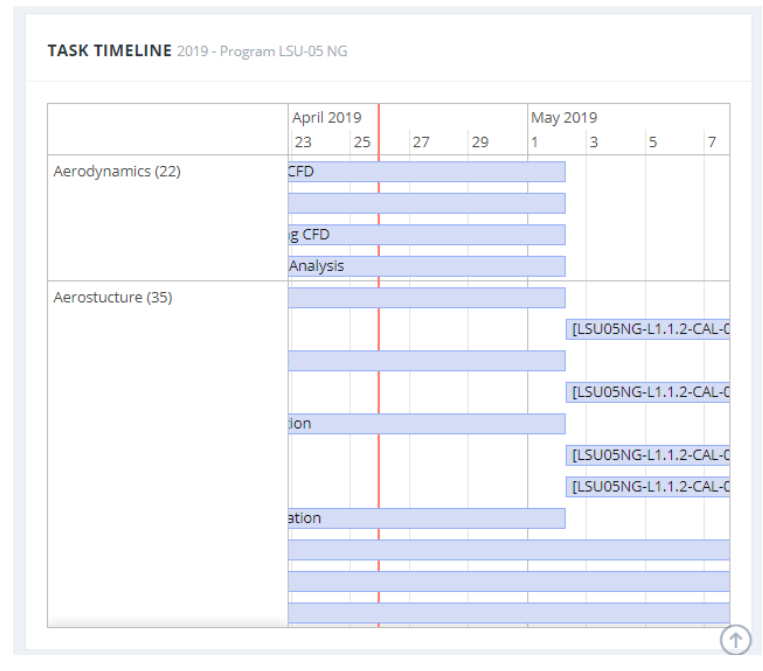

Gambar 6. Timeline 
Selain timeline, terdapat Diagram Progres untuk mengetahui persentase pengerjaan dari masing-masing tim. Diagram ini bertujuan untuk mengetahui keaktifan dari masing-masing tim.

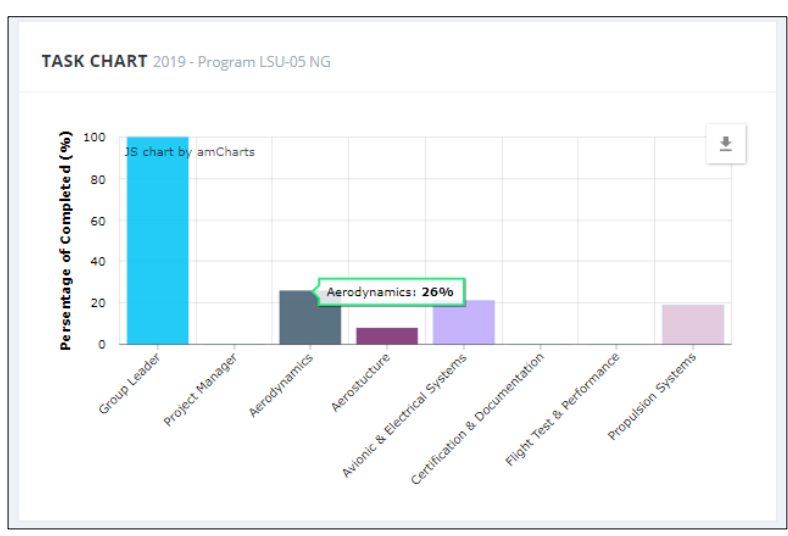

Gambar 7. Diagram Progres

\section{Kesimpulan}

Penulis mencoba simpulkan bahwa sistem yang dibangun berdasarkan fungsi sesuai dengan yang diharapkan. Sehingga proses dalam menjalankan fungsi DOA berjalan dengan baik. Salah satu pengujian yang dilakukan sebagai berikut.

Tabel 2. Pengujian dengan black-box

\begin{tabular}{|l|l|}
\hline Data & $\begin{array}{l}\text { Nama Dokumen: Format } \\
\text { Lembar Instruksi } \\
\text { File: Lembar Instruksi.doc } \\
\text { Size: 33,4KB }\end{array}$ \\
\hline $\begin{array}{l}\text { Hasil yang } \\
\text { diharapkan }\end{array}$ & $\begin{array}{l}\text { Sistem dapat melakukan } \\
\text { penyimpanan data ke } \\
\text { database dan file } \\
\text { dokumen ke server. }\end{array}$ \\
\hline Pengamatan & $\begin{array}{l}\text { Data dan file dokumen } \\
\text { dapat disimpan oleh } \\
\text { sistem }\end{array}$ \\
\hline Status & Valid \\
\hline
\end{tabular}

Berdasarkan analisis SWOT, penulis mencoba simpulkan bahwa sistem yang dibangun memiliki banyak kelebihan dibandingkan sistem yang ada sebelumnya karena lebih banyak kekuatan pada sistem yang telah dibangun.

Analisis SWOT meliputi faktor internal kekuatan (Strenghts) dan kelemahan (Weaknesess) serta faktor eksternal yaitu peluang (Opportunity) dan ancaman (Treats) yang terdapat pada sistem dokumentasi ini. Kekuatan yang ada pada sistem ini yaitu pengerjaan dokumen lebih cepat, paperless, memudahkan pencarian dokumen dan mengetahui waktu pengerjaan dokumen. Sedangkan untuk kelemahannya yaitu sistem hanya dapat diakses oleh jaringan kantor. Adapun peluang yang didapatkan yaitu beberapa proses kegiatan yang dilakukan belum terkomputerisasi dapat dibuatkan sistem dengan metode yang sama. Dan ancaman yang dapat terjadi yaitu jika terjadi masalah pada server yang digunakan yang mengakibatkan sistem tidak dapat diakses dan dokumen desain tidak dapat dibuka, namun hal ini dapat dilakukan pencegahan dengan melakukan backup server.

\section{Saran}

Penulis mengharapkan penelitian ini dapat bermanfaat, untuk selanjutnya dapat dikembangkan dan ditambahkan sehingga menjadi penelitian berkelanjutan. Kebutuhan dalam menjalankan fungsi DOA akan selalu berkembang sehingga akan banyak pengembangan dari penelitian yang sudah dilakukan.

Saran untuk pengembangan selanjutnya, sistem ini diharapkan dapat dikembangkan dalam bentuk aplikasi mobile, sehingga lebih memudahkan pengguna dalam mengakses sistem tersebut.

\section{References}

Basuki, A. P. (2014). Proyek Membangun Website Berbasis PHP dengan Codeigniter. Yogyakarta: Lokomedia.

Destiningrum, M., \& Adrian, Q. J. (2017). Sistem Informasi Penjadwalan Dokter Berbassis Web dengan Menggunakan Framework Codeigniter (Studi Kasus: Rumah Sakit Yukum Medical Centre). Jurnal TEKNOINFO, 11(2), 30-37.

Dhining, D., Rokhayati, Y., \& Kurniawan, D. E. (2017). Penerapan Replikasi Data pada Aplikasi Ticketing Menggunakan Slony PostgreSQL. Journal of Applied Informatics and Computing (JAIC), 1(1), 9-18.

Erinton, R., Negara, R. M., \& Sanjoyo, D. D. (2017). Analisis Performasi Framework Codeigniter dan Laravel Menggunakan Web Server Apache. e-Proceeding of Engineering, 35653572.

Fajarianto, O. (2016). Prototype Pelayanan Akademik terhadap Komplain Mahasiswa Berbasis Mobile. JURNAL LENTERA ICT, 3(1), 54-60.

Harminingtyas, R. (2018). Perancangan Website Sebagai Media Promosi dan Informasi. Journal Of Informatic Pelita Nusantara, 3(1), 82-86.

Jogiyanto, H. (2017). Analisis dan Desain (Sistem Informasi Pendekatan Terstruktur Teori dan Praktek Aplikasi Bisnis). Yogyakarta: Andi. 
Kadir, A. (2017). Pengenalan sistem informasi edisi revisi. Yogyakarta: Andi.

Ningrum, F., Suherman, D., Aryanti, S., Prasetya, H., \& Saifudin, A. (2019). Pengujian Black Box pada Aplikasi Sistem Seleksi Sales Terbaik Menggunakan Teknik Equivalence Partitions. Jurnal Informatika Universitas Pamulang, 125.
Permana, A. A., \& Nurnaningsih, D. (2018). Rancangan Aplikasi Pengamanan Data dengan Algoritma Advanced Encyption Standard (AES). Jurnal Teknik Informatika, 11(2), 177186. 